\title{
Confirmatory factor analysis of the Nepean Dysphoria Scale in a
}

\section{clinical sample}

David Berle ${ }^{1,2}$, Vladan Starcevic ${ }^{3}$, Kirupamani Viswasam ${ }^{4}$, Denise Milicevic ${ }^{5}$, Anthony Hannan ${ }^{5}$, Vlasios Brakoulias $^{3}$, Zachary Steel $\left.\right|^{2,5,7}$

1. Discipline of Clinical Psychology, University of Technology Sydney, Australia.

2. School of Psychiatry, University of New South Wales Sydney, Australia.

3. Sydney Medical School - Nepean, Discipline of Psychiatry, University of Sydney, Sydney/Penrith, Australia.

4. Department of Psychiatry, Nepean Hospital, Penrith, Australia.

5. Nepean Anxiety Disorders Clinic, Nepean Blue Mountains Local Health District, Australia.

6. St John of God Health Care, Richmond Hospital, North Richmond, Australia.

7. Black Dog Institute, Randwick, Australia.

Address for correspondence:

David Berle

Discipline of Clinical Psychology

Graduate School of Health

University of Technology Sydney

Building 7

67 Thomas Street

Ultimo NSW 2007

Australia

Ph: +61 295149221

Email: david.berle@uts.edu.au 


\title{
Confirmatory factor analysis of the Nepean Dysphoria Scale in a
}

\author{
clinical sample
}




\begin{abstract}
The construct of dysphoria has been described inconsistently across a broad range of psychopathology. The term has been used to refer to an irritable state of discontent, but is also thought to incorporate anger, resentment and nonspecific symptoms associated with anxiety and depression, such as tension and unhappiness. The Nepean Dysphoria Scale has been developed to allow assessment of dysphoria, but its factor structure has not yet been investigated in clinical samples. We aimed to determine the latent structure of dysphoria as reflected by the Nepean Dysphoria Scale, using a clinical sample. Adults $(N=206)$ seeking treatment at a range of mental health services were administered the Nepean Dysphoria Scale. Four putative factor structures were investigated using confirmatory factor analysis: a single-factor model, a hierarchical model, a bifactor model and a four-factor model as identified in previous studies. No model fit the data except for a four-factor model when a revised 22-item version of the original 24-item scale was investigated. A four-factor structure similar to that identified in non-clinical samples was supported, albeit following the removal of two items. The Nepean Dysphoria Scale appears to have utility for the assessment of dysphoria in routine clinical settings.
\end{abstract}

\title{
Keywords
}

Psychometric, clinical sample, validity, construct, scale, interpersonal. 


\section{Introduction}

The concept of dysphoria has been invoked in relation to a wide range of psychiatric conditions. It has been reported in relation to mood-related menstrual changes, as a feature of mixed mood states in bipolar disorder, as well as in the context of dissatisfaction with one's gender [1]. Moreover, there appears to be substantial variation in the features which are thought to define dysphoria. For example, in some instances, dysphoria or dysphoric mood is assumed to refer to a mild or subclinical state of depression [2-4] in others, the core feature of dysphoria appears to be one of general distress arising from discontent (e.g., with one's gender; [5]). In posttraumatic stress disorder (PTSD), dysphoria has been referred to as a non-specific mix of memory impairment, diminished interest, feelings of detachment, restricted affect, sleep disturbance, irritability and concentration difficulties [6]. Dysphoria has also been considered one of the key features of borderline personality disorder [7].

The lack of consistency in the use of dysphoria may in part arise from the apparent complexity of the state. At the most basic level, dysphoria could be described as an irritable state of discontent $[8,9]$. However, associated features of anger, aggression, hostility and suspiciousness/paranoia have also been described [9] and observed in empirical investigations [10]. Thus, not only is there inconsistency in the use of the term, but there is a lack of clarity regarding its boundaries.

Achieving conceptual clarity and consistency will be important if the concept of dysphoria is to demonstrate clinically utility. For instance, if dysphoria is best understood as a circumscribed state of discontent, it may give rise to a different focus of treatments compared to a broader concept that is characterized by prominent interpersonal mistrust and suspiciousness. An improved understanding of dysphoria may allow researchers to account for the relationships between psychological disorders and various difficulties that cannot be explained by anxiety, depression or disorder-specific symptoms alone. For instance, in PTSD, the dysphoria component alone, but not overall PTSD symptoms, appears to prospectively predict relationship dysfunction [11]. 
In an effort to understand the latent structure of dysphoria and to provide an instrument to allow for the quantification of dysphoric states, we developed the Nepean Dysphoria Scale (NDS; [12]). The scale was constructed on the basis of our model of dysphoria [9], with its items reflecting irritability, unhappiness, dissatisfaction and a tendency to attribute one's distress to external factors. A preliminary exploratory factor analysis indicated four factors including irritability, discontent, surrender and interpersonal resentment [12]. The four-factor structure has since been replicated using an Italian translation of the scale [13]. However, both studies relied on student samples, thus precluding inferences about the latent structure of dysphoria in clinical samples.

Aside from the four-factor structure suggested by previous studies, three alternative structures warrant investigation. The first possibility is that the diverse range of symptoms, including irritability, interpersonal resentment and surrender reflected by the concept of dysphoria, might be best described by a single dysphoria factor. This would be consistent with some domains of the psychiatric literature, such as PTSD, where a unitary dysphoria factor has been supported alongside other symptom clusters [6].

A second possibility is a hierarchical model whereby each of the abovementioned four factors are subsumed within a second-order dysphoria factor. This would be consistent with the notion that a broad proclivity to dysphoria might give rise to irritability, discontent, surrender and interpersonal resentment, and in turn, endorsement of the NDS items that reflect these factors. While this model of dysphoria may not be as broad as the notion of a general psychopathology factor, which subsumes all other specific dimensions of psychological symptoms [14], the apparent hierarchical structure of psychopathology symptoms certainly leaves this as a possibility.

A final alternative is a bifactor model, whereby each item loads on its respective factor (irritability, discontent, surrender and interpersonal resentment), while also directly loading on an overall dysphoria factor. In contrast to the hierarchical model, the bifactor model specifies that a single general dysphoria factor directly accounts for some of the common variance on each item. 
We therefore aimed to investigate four different factor structures of the NDS: the fourfactor structure suggested by the exploratory factor analysis of the non-clinical sample of [12], a single-factor model, a hierarchical model and a bifactor model. Ultimately, further investigation of the factor structure of the NDS in clinical samples might provide a basis for a psychometrically valid measure of dysphoria with transdiagnostic clinical utility and thus a potential to be used in a variety of clinical settings.

\section{Method}

Participants $(N=206$, mean age $=39.3$ years, $S D=11.2 ; 113(54.9 \%)$ female) were recruited from a specialized anxiety disorders clinic $(n=122 ; 59.2 \%)$, a residential treatment program for PTSD $(n=$ $50,24.3 \%)$, a general outpatient psychiatry service $(n=26 ; 12.6 \%)$ and acute mental health service $(n=8 ; 3.9 \%)$. A previous paper [10] reports on the relationship between dysphoria and general psychopathology using a subset of the present sample $(n=96)$.

\section{Instrument}

The Nepean Dysphoria Scale (NDS) requires respondents to provide ratings of the frequency on a scale from 0 ("not at all") to 4 ("always [every day, most of the time]") with which they have experienced 24 dysphoria-relevant symptoms (e.g., "Have you felt as if nothing seemed right?"; “Have you felt that people don't care about you?") for the 1-week period preceding administration. Total scores and scores on each of the four putative factors (Discontent, Surrender, Irritability and Interpersonal Resentment) are calculated as the means of the corresponding items. The two previous validation studies of the scale reported an excellent internal consistency (Cronbach's $\alpha$ ranging from 0.85 to 0.96 [12] and from 0.85 to 0.90 [13]), as well as expected correlations with theoretically related variables.

\section{Data analysis}


Confirmatory factor analyses of the four aforementioned factor structures were conducted in R 3.3.1 using the Lavaan package [15]. Weighted least squares means and variance adjusted (WLSMV) estimation were used, given the advantages of this approach for ordered categorical variables [16], such as the 5-point ordered-category scale of the NDS.

\section{Model fit}

A significant chi-square test suggests a difference between the sample-implied and model-implied variances, and is indicative of poor model fit. However, chi-square tests are sensitive to sample size, so we assessed the overall fit of each model by considering absolute and incremental fit indices (i.e., the Comparative Fit [CFI] and Tucker-Lewis Indices [TLI]), as well as the Root Mean Square Error of Approximation (RMSEA) residual-based index. Consistent with established standards [17], values of at least 0.95 for CFI and TLI were considered acceptable and values below 0.06 were considered acceptable for RMSEA.

Re-specification of models that did not fit the data was conducted with reference to modification indices and the conceptual basis of the respective scale items.

\section{Results}

Table 1 shows the range of disorders identified amongst the clinical sample with the most prevalent being a primary diagnosis of PTSD or various anxiety and depressive disorders. Results of confirmatory factor analyses of the NDS are presented in Table 2 and the findings for each model are discussed below.

Single factor model 
This model did not appear to fit the data. The chi-square $p$-value was $<0.001$, and although the CFI and TLI values were adequate, the $90 \%$ RMSEA confidence interval ranged from 0.15 to 0.17 . Given the parsimonious structure of the single factor model, no modifications were indicated.

\section{Hierarchical model}

This model also did not appear to fit the data. While CFI and TFI values were each acceptable, the $90 \%$ RMSEA confidence interval ranged from 0.13 to 0.15 , which is outside the range of existing conventions for model fit. The greatest extent of misspecification was the loading of item 3 ("Have you felt others messed things up for you") on the Resentment factor (modification index value = 168.24). As this did not appear to be incongruous with the construct of dysphoria, no re-specification of the model was conducted.

\section{Bifactor model}

The bifactor model did not appear to fit the data. Like the hierarchical model, CFI and TFI values were acceptable, however the 90\% RMSEA confidence interval ranged from 0.11 to 0.13 . The greatest extent of misspecification was again the loading of item 3 ("Have you felt others messed things up for you") on the Resentment factor (modification index value $=182.11$ ). As this did not appear to be incongruous with the construct of dysphoria, no re-specification of the model was conducted.

Four-factor model of Berle \& Starcevic (2012)

This model displayed evidence of misfit to the data, given that the chi-square value was significant and RMSEA values exceeded 0.10. The highest modification index values were for item 11 on the Surrender (230.49) and Discontent (228.83) factors. Item 11 (“Have you felt on edge?") is potentially ambiguous and not necessarily specific for the dysphoria construct, also suggesting hyperarousal more generally. For this reason, we repeated the analysis after excluding item 11. 
Re-specification of the model without item 11 did not result in an adequate fit $\left(\chi^{2}=562.12\right.$, p-value $<0.001$ and $90 \%$ RMSEA confidence interval ranged from 0.08 to 0.10$)$. The three highest modification indices scores were for item 24 on the Irritability (207.51), Resentment (181.37) and Discontent (79.89) factors, respectively. Given that item 24 (“Has everything been getting on your nerves?") is also potentially ambiguous, with "nerves" referring to a state of anger, irritability or anxiety, we repeated the analysis after excluding item 24.

Excluding items 11 or 24 resulted in a four-factor model that had acceptable statistical fit to the data structure $\left(\chi^{2}=339.9, p\right.$-value $<0.001, C F I=1.00, T L I=0.97$ and $90 \%$ RMSEA confidence interval ranged from 0.05 to 0.07$)$. Modification indices and conceptual considerations did not suggest the exclusion of any other items, which we also note were relatively unambiguous. This indicates that the remaining items could be considered consistent with the overall construct of dysphoria.

\section{Discussion}

The term dysphoria has been used to characterize a wide range of psychopathology and mental disorders. Inconsistent understanding of the structure and breadth of dysphoria symptoms calls for a systematic approach to delineating the scope and dimensions of the construct among individuals with mental disorders. In an attempt to bring definitional and measurement clarity to the study of dysphoria, we developed the NDS to assess key components of the dysphoria construct. Initial validation of the NDS identified a four-factor structure incorporating irritability, discontent, surrender and interpersonal resentment. An outstanding limitation of the NDS is that its factor structure has only been investigated in non-clinical samples.

The first aim of the present study was to determine whether this four-factor model could be confirmed in a group of treatment-seeking individuals with mental disorders. While the structure of the original 24-item scale with four factors was not fully supported, the elimination of two 
conceptually questionable items led to an acceptable fit. In clinical samples, the NDS might therefore best be understood as a 22 -item measure comprised of four subscales which correspond to the respective factors (Table 3).

Three other theoretically plausible structures, a single factor, a hierarchical structure and a bifactor structure, were also explored. The single factor model did not fit the data, suggesting that dysphoria is not a unitary construct, but likely comprised of its own distinct domains. A hierarchical model whereby a higher order "Dysphoria" factor would subsume the others, received no support, although the four factors were correlated with each other. A bifactor model was also did not fit the data, suggesting that the items did not maintain a separate loading on an overall dysphoria factor that was independent of each of the respective individual factors.

Use of the NDS could be informative in clinical settings. For example, it would be useful to administer the NDS to patients with PTSD insofar as dysphoria-related symptoms represent the nonspecific features of PTSD (whereby trauma-related intrusive experiences, avoidance and hypervigilance are considered the specific and defining features of PTSD [18]). High scores on the NDS or on some of its subscales such as discontent in PTSD patients might alert clinicians to explore the potential causes of dysphoria or discontent. This would help inform the therapeutic approach beyond only addressing the specific features of PTSD.

The present study has a number of limitations. For instance, while some study participants were administered a semi-structured diagnostic interview, others had their diagnoses based on clinicians' assessment. A related issue is the frequency of co-occurring mental disorders, including personality disorders, which was not systematically assessed. However, clinician-administered semistructured diagnostic interviews are rarely used in ordinary clinical settings and the study sample appeared to be representative of treatment-seeking individuals with a variety of mental disorders outside of the realm of psychoses and severe bipolar disorders and therefore suitable for investigating the concept of dysphoria. Second, the overall sample size was relatively small for a confirmatory factor analysis, calling for additional investigation of the factor structure with larger 
samples. Finally, our investigation focused on the factor structure and construct validity of the NDS, without examining its other psychometric properties. However, a study using the 24 -item version of the NDS showed expected convergent associations with other key measures of depression and anxiety in a subset of the present sample [10].

In conclusion, a confirmatory factor analysis of the NDS in a heterogeneous clinical sample confirmed a four-factor model, with a proviso that two items should be omitted from the NDS. This provides further support for clinical use of the NDS, a novel instrument for assessing the transdiagnostic construct of dysphoria and its components. 


\section{References}

1. Starcevic V, Rossi Monti M, D’Agostino A, Berle D. Will DSM-5 make us feel dysphoric? Conceptualisation(s) of dysphoria in the most recent classification of mental disorders. Aust N Z J Psychiatry. 2013; 47:954-5.

2. Berle D, Moulds ML. Emotional Reasoning Processes and Dysphoric Mood: CrossSectional and Prospective Relationships. PLoS ONE. 2013; 8:6.

3. Ellis AJ, Beevers CG, Wells TT. Emotional dysregulation in dysphoria: Support for emotion context insensitivity in response to performance-based feedback. J Behav Ther Exp Psychiatry. 2009; 40:443-454.

4. Teasdale JD, Cox SG. Dysphoria: self-devaluative and affective components in recovered depressed patients and never depressed controls. Psychol Med. 2001;31:13111316.

5. Beek TF, Cohen-Kettenis PT, Kreukels BPC (2016). Gender incongruence/gender dysphoria and its classification history. Int Rev Psychiatry. 2016;28:5-12.

6. Simms L, Watson D, Doebbeling BN. Confirmatory factor analyses of posttraumatic stress symptoms in deployed and nondeployed veterans of the Gulf War. J Abnorm Psychol. 2002;111:637-647.

7. Rossi Monti M, D'Agostino A. Borderline personality disorder from a psychopathological-dynamic perspective. J Psychopathol. 2014;20:451-461.

8. Musalek M, Griengl H, Hobl B, Sachs G, Zoghlami A. Dysphoria from a transnosological perspective. Psychopathol. 2000;33:209-214.

9. Starcevic V (2007). Dysphoric about dysphoria: Towards a greater conceptual clarity of the term. Australas Psychiatry.2007;15:9-13.

10. Starcevic V, Berle D, Viswasam K, Hannan A, Milicevic D, Brakoulias V, Dale E. Specificity of the relationships between dysphoria and related constructs in an outpatient sample. Psychiatr Quart. 2015;86:459-469. 
11. Erbes CR, Meis LA, Polusny MA, Compton JS, Wadsworth SM. An examination of PTSD symptoms and relationship functioning in US Soldiers of the Iraq War over time. J Traum Stress. 2012;25:187-190.

12. Berle D, Starcevic V. Preliminary validation of the Nepean Dysphoria Scale. Australas Psychiatry. 2012;20:322-326.

13. D’Agostino A, Manganelli E, Aportone A, Rossi Monti M, Starcevic V. Development, cross-cultural adaptation process and preliminary validation of the Italian version of the Nepean Dysphoria Scale. J Psychopathol. 2016;22:149-156.

14. Caspi A, Houts RM, Belsky DW, Goldman-Mellor SJ, Harrington H, Israel S, Meier MH, Ramrakha S, Shalev I, Poulton R, Moffitt TE. The $p$ factor: One general psychopathology factor in the structure of psychiatric disorders? Clin Psychol Sci. 2014;2:119-137.

15. Rosseel Y. Lavaan: An R package for structural equation modeling. J Stat Soft. 2012; 48:1-36.

16. Beauducel A, Herzberg PY. On the performance of maximum likelihood versus means and variance adjusted weighted least squares estimation in CFA. Struct Equ Modeling. 2006;13:186-203.

17. Hu L-I, Bentler PM. Cutoff criteria for fit indexes in covariance structure analysis: Conventional criteria versus new alternatives. Struct Equ Modelling. 1999; 6:1-55. 18. Gootzeit J, Markon K. Factors of PTSD: Differential specificity and external correlates. Clin Psychol Rev. 2011;31:993-1003. 
Table 1. Primary DSM-IV diagnoses in the study sample $(N=206)$.

Posttraumatic stress disorder

Panic disorder with or without agoraphobia

Generalised anxiety disorder

Major depressive disorder or dysthymia

Social anxiety disorder

Specific phobia

Obsessive-compulsive disorder

Anxiety disorder not otherwise specified

Hypochondriasis

Other
42

35

$\%$ of overall sample

25.24

20.39

22

10.68

15

11

8

8

3

1.46

10

4.85

\footnotetext{
\# Diagnosis of posttraumatic stress disorder was based on DSM-5 criteria.

^ "Other" includes histrionic traits, irritable bowel syndrome, chronic pain and health anxiety not meeting the diagnostic criteria for hypochondriasis.

diagnoses.
} 
Table 2. Results of confirmatory factor analyses of the Nepean Dysphoria Scale.

\begin{tabular}{|c|c|c|c|c|c|}
\hline \multirow[t]{2}{*}{ Model } & \multirow[t]{2}{*}{$\chi^{2}, d f, p$-value } & \multirow[t]{2}{*}{$\mathrm{CFI}$} & \multirow[t]{2}{*}{ TLI } & \multicolumn{2}{|c|}{ RMSEA 90\% Cl } \\
\hline & & & & Lower & Upper \\
\hline 1. Single-factor model & $1557.10,252,<0.001$ & 0.98 & 0.98 & 0.15 & 0.17 \\
\hline 2. Hierarchical model & $1140.94,248,<0.001$ & 0.99 & 0.98 & 0.13 & 0.15 \\
\hline 3. Bifactor model & $881.29,228,<0.001$ & 0.99 & 0.99 & 0.11 & 0.13 \\
\hline $\begin{array}{l}\text { 4. Four-factor model of } \\
\text { Berle and Starcevic (2012) }\end{array}$ & $820.70,246,<0.001$ & 0.99 & 0.99 & 0.10 & 0.12 \\
\hline $\begin{array}{l}\text { 4a. Revised four-factor } \\
\text { model without item } 11\end{array}$ & $562.12,224,<0.001$ & 0.99 & 0.99 & 0.08 & 0.10 \\
\hline $\begin{array}{l}\text { 4b. Revised four-factor } \\
\text { model without items } 11 \\
\text { and } 24\end{array}$ & $339.91,203,<0.001$ & 1.00 & 0.97 & 0.05 & 0.07 \\
\hline
\end{tabular}

CFI = Comparative Fit Index, TLI = Tucker-Lewis Index, RMSEA = Root Mean Square Error of Approximation. 
Table 3. Subscales of the Nepean Dysphoria Scale representing the four factors derived from confirmatory

\begin{tabular}{|c|c|c|c|}
\hline Irritability & Discontent & Surrender & Interpersonal resentment \\
\hline $\begin{array}{l}\text { Item } 3 \text { "Have you felt that } \\
\text { others have messed up } \\
\text { things for you?" }\end{array}$ & $\begin{array}{l}\text { Item } 1 \text { "Have you felt } \\
\text { discontent?" }\end{array}$ & $\begin{array}{l}\text { Item } 2 \text { "Have things got the } \\
\text { better of you?" }\end{array}$ & $\begin{array}{l}\text { Item } 9 \text { “Have you felt that } \\
\text { people shouldn't be } \\
\text { trusted?" }\end{array}$ \\
\hline $\begin{array}{l}\text { Item } 5 \text { "Have you felt } \\
\text { impatient with other } \\
\text { people?" }\end{array}$ & $\begin{array}{l}\text { Item } 6 \text { "Have you felt } \\
\text { that you achieved } \\
\text { nothing?" }\end{array}$ & $\begin{array}{l}\text { Item } 4 \text { "Has it been hard to } \\
\text { relax?" }\end{array}$ & $\begin{array}{l}\text { Item } 12 \text { “Have you felt that } \\
\text { people don't care about } \\
\text { you? }\end{array}$ \\
\hline $\begin{array}{l}\text { Item } 7 \text { "Have you felt that } \\
\text { you might lose control and } \\
\text { hit someone?" }\end{array}$ & $\begin{array}{l}\text { Item } 8 \text { "Have you felt } \\
\text { as if nothing seemed } \\
\text { right?" }\end{array}$ & $\begin{array}{l}\text { Item } 14 \text { "Have you felt that } \\
\text { everything was too much?" }\end{array}$ & $\begin{array}{l}\text { Item } 15 \text { "Have you felt that } \\
\text { people are not fair towards } \\
\text { you?" }\end{array}$ \\
\hline $\begin{array}{l}\text { Item } 13 \text { "Have you been } \\
\text { losing your temper?" }\end{array}$ & $\begin{array}{l}\text { Item } 10 \text { "Have you felt } \\
\text { like giving up?" }\end{array}$ & $\begin{array}{l}\text { Item } 17 \text { "Have you felt like } \\
\text { you couldn't cope } \\
\text { anymore?" }\end{array}$ & $\begin{array}{l}\text { Item } 23 \text { "Have you felt that } \\
\text { people are against you?" }\end{array}$ \\
\hline $\begin{array}{l}\text { Item } 16 \text { "Have you felt } \\
\text { cranky?" }\end{array}$ & $\begin{array}{l}\text { Item } 19 \text { "Have you felt } \\
\text { unhappy?" }\end{array}$ & $\begin{array}{l}\text { Item } 22 \text { "Have you felt } \\
\text { overwhelmed by life?" }\end{array}$ & \\
\hline $\begin{array}{l}\text { Item } 18 \text { "Have you been } \\
\text { feeling angry towards other } \\
\text { people?" }\end{array}$ & $\begin{array}{l}\text { Item } 21 \text { "Have you felt } \\
\text { miserable?" }\end{array}$ & & \\
\hline $\begin{array}{l}\text { Item } 20 \text { "Have you felt easily } \\
\text { annoyed by what others say } \\
\text { or do?" }\end{array}$ & & & \\
\hline
\end{tabular}




\section{Author biography}

David Berle: David is a Senior Lecturer and National Health and Medical Research Council (NHMRC) Early Career Fellow in the Graduate School of Health at the University of Technology Sydney (UTS). He is also a conjoint Senior Lecturer in the School of Psychiatry at UNSW Sydney. His research aims to optimise treatment outcomes for people with posttraumatic and anxiety disorders.

Vladan Starcevic: Vladan is Associate Professor at Sydney Medical School - Nepean of the University of Sydney, Consultant Psychiatrist and Head of the Department of Psychiatry at Nepean Hospital, Sydney/Penrith, Australia.

Kirupamani Viswasam: Kirupamani is a Psychologist in Research and Research Assistant working with the Department of Psychiatry at Nepean Hospital, Penrith, Australia. She is involved with various research related to anxiety disorders and OCD as well as clinical trials being conducted by the Department of Psychiatry. She is also currently working on her PhD on 'The prevalence and trajectory of anxiety disorders during pregnancy'.

Denise Milicevic: Denise is a Senior Clinical Psychologist and Team Leader at the Nepean Anxiety Disorders Clinic, Mental Health Service at Nepean Blue Mountains Local Health District. Her research interests are in the areas anxiety disorders and hoarding disorder, in particular assessing treatment outcomes and research finding in routine clinical practice.

Anthony Hannan: Anthony is a Senior Clinical Psychologist at the Nepean Anxiety Disorders Clinic in Sydney, Australia. His main area of interest is the treatment of anxiety disorders.

Vlasios Brakoulias: Dr Brakoulias is a Conjoint Senior Lecturer in the Discipline of Psychiatry of the Sydney Medical School at Nepean Hospital. He also works as a Senior Staff Specialist at the Mental Health Centre of Nepean Hospital. Dr Brakoulias leads the Nepean Obsessive-Compulsive and Related Disorders University Clinic and he is committed to improving treatments for patients with obsessivecompulsive disorder.

Zachary Steel: Zachary is the St John of God Health Care Professorial Chair in Trauma and Mental Health at UNSW Sydney. His program of research has examined the prevalence, social determinants, and intervention models for mental health problems across diverse communities and settings with a particular focus on traumatic stress, forced displacement, conflict and complex emergencies. 
Acknowledgements: Dominic Hilbrink, Laura Hardaker, Clare Russell-Williams, Rachel Kiely and all of the allied health staff at St John of God Health Care Richmond Hospital are thanked for their assistance with participant recruitment. Brian Skepper and Erin Dale of the Nepean Anxiety Disorders Clinic also assisted with participant recruitment.

Compliance with Ethical Standards: All procedures involving human participants were in accordance with the ethical standards of the institutional and/or national research committee and with the 1964 Helsinki declaration. The study was approved by the Nepean Blue Mountains Local Health District Human Research Ethics Committee (Ref 07/068-07/NEPEAN/14) and the St John of God Health Care Human Research Ethics Committee (Ref: 839).

Funding: This research was supported by a Defence Health Foundation Grant awarded to the first and last authors (DB \& ZS).

Potential conflict of Interest: The authors declare that they have no conflict of interest. 